Available online on 15.07.2020 at http://jddtonline.info
(c) 2011-20, publisher and licensee JDDT, This is an Open Access article which permits
unrestricted non-commercial use, provided the original work is properly cited

Open $\odot$ Access

Research Article

\title{
Polyphenols contents and antioxidant Activity of extracts from Leaves and flowers of Thymelaea hirsuta
}

\author{
Mounira Merghem*, Saliha Dahamna and Seddik Khennouf \\ Laboratory of Phytotherapy Applied to Chronic Diseases, Faculty of Natural and Life Sciences, Ferhat Abbas University, Sétif 19000, Algeria
}

\begin{abstract}
Thymelaea hirsuta is a medicinal plant, belonging to the genus Thymelaea (Thymelaeaceae) widely used in Mediterranean countries especially in Algeria. In this study, we have evaluated the total polyphenols and flavonoids contents of methanolic and aqueous extracts of Leaves and flowers of Thymelaea hirsuta as well as its antioxidant activity using the DPPH (2'2-diphenylpicrylhydrazyl) and $\beta$-carotene /linoleic acid bleaching assays. The yield of the methanolic and aqueous extract was $11,55 \%$ and $13,25 \%$ respectively. The total polyphenols content of the methanolic extract was 295, $22 \mu \mathrm{g} \mathrm{GAE} / \mathrm{mg}$ extract and flavonoids was 09, $40 \mu \mathrm{g} \mathrm{QE} / \mathrm{mg}$ and 26, $42 \mu \mathrm{g} \mathrm{RE} / \mathrm{mg}$ extract. The total polyphenols content of the aqueous extract was 57, $95 \mu \mathrm{g} \mathrm{GAE} / \mathrm{mg}$ extract and flavonoids was $4.59 \mu \mathrm{g} \mathrm{QE} / \mathrm{mg}$ and $10.66 \mu \mathrm{g} \mathrm{RE} / \mathrm{mg}$ extract. In the DPPH assay, methanolic extract showed the higher scavenging capacity $\left(\mathrm{IC}_{50}=0.03 \pm 0.004 \mathrm{mg} / \mathrm{ml}\right.$ ), followed by aqueous extract with $\mathrm{IC}_{50}$ of $0.275 \pm$ $0.019 \mathrm{mg} / \mathrm{ml}$. In the test of $\beta$-carotene /linoleic acid, the percentage of inhibition was $39.1 \pm 1.33 \%$ for the aqueous extract and $41.05 \pm 2.72 \%$ for methanolic extract.
\end{abstract}

Keywords: Thymelaea hirsuta, antioxidant activity, polyphenols, DPPH scavenging, $\beta$-carotene.

Article Info: Received 02 May 2020; Review Completed 23 June 2020; Accepted 02 July 2020; Available online 15 July 2020

Cite this article as:

Merghem M, Dahamna S, Khennouf S, Polyphenols contents and antioxidant Activity of extracts from Leaves and flowers of Thymelaea hirsuta, Journal of Drug Delivery and Therapeutics. 2020; 10(4):108-111 http://dx.doi.org/10.22270/jddt.v10i4.4159

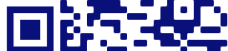

*Address for Correspondence:

Mounira Merghem, Laboratory of Phytotherapy Applied to Chronic Diseases, Faculty of Natural and Life Sciences, Ferhat Abbas University, Sétif 19000, Algeria

\section{INTRODUCTION}

The oxygen consumption inherent in cell growth leads to the generation of a series of reactive oxygen species (ROS). These ROS play a positive role in energy production, phagocytosis and regulation of cell growth, intercellular signalling, and synthesis of biologically important compounds. However, ROS may also be very damaging, they can attack the lipids of cell membranes and DNA. The oxidation induced by ROS can result in cell membrane disintegration, membrane protein damage and DNA mutation, which can further initiate or propagate the development of many diseases 1,2 . such as diabetes, cancer, inflammation, genotoxicity, alzheimers disease and cataracts, retinopathy, rheumatism, skin disease porphyria and senile dementia stroke 3,4 .

antioxidant is any substance that delays, prevents or removes oxidative damage to a target molecule 5 . Antioxidants can scavenge free radicals and protect the human body from the oxidative stress that eventually, protect human body from cardiovascular disease, cancer, high blood pressure, diabetes and obesity ${ }^{6}$.
Antioxidant compounds such as flavonoids, tannins, coumarins, curcumanoids, xanthons, lignans and terpenoids are found in different plant parts (e.g., fruits, leaves and seeds). Therefore, there is growing interest in separating these bioactive compounds and using them as natural antioxidants 7 .

Thymelaea hirsuta commonly know as Methnane is a shrub of the family of Thymelaeaceae. It is native from the Canary Island, Mediterranean region, north of central Europe and Eastern Central Asia 8, 9. It has been traditionally used in folk medicine as antiseptic, antimelanogenesis 9, 10, It was shown that the aqueous extract of Thymelaea hirsuta possesses both hypoglycemic and antidiabetic effects in normoglycemic and streptozotocin induced diabetic rats ${ }^{11}$. studies mentioned that the Thymelaea hirsuta's aerial parts exhibited a very notable antioxidant activity 12,13 .

\section{MATERIALS AND METHODS}

\section{Plant material}

Thymelaea hirsuta plant material was collected from Wilaya of Sétif, Northeast of Algeria. 


\section{Preparation of plant extract}

\section{Aqueous extract}

The leaves and flowers of Thymelaea hirsuta were washed in running water, dried and powdered. $100 \mathrm{~g}$ of powder was mixed with $1 \mathrm{~L}$ of boiled distilled water $\left(100{ }^{\circ} \mathrm{C}\right)$ and was placed at room temperature during $72 \mathrm{~h}$, The resulting mixture was filtered and then evaporated in rotary vacuum evaporator at $45^{\circ} \mathrm{C}$.

\section{Methanolic extract}

The methanolic extract was obtained by maceration in water/methanol mixture $(30: 70)$ for $48 \mathrm{~h}$. The resultant extract was filtered through Wattman paper and the solvent was removed by rotary evaporator under reduced pressure at $45^{\circ} \mathrm{C}$.

\section{Determination of total polyphenols content}

Total phenolic content was determined using Folin-Ciocalteu method, according to ${ }^{14}$ with slight modifications. A volume of $100 \mu \mathrm{l}$ of the extract was mixed with $500 \mu \mathrm{l}$ of FolinCiocalteau (diluted $10 \%$ in distilled water). After 4 min, 400 $\mu \mathrm{l}$ of sodium carbonate solution $\mathrm{Na}_{2} \mathrm{CO}_{3}(75 \mathrm{~g} / \mathrm{l})$ was added to the mixture, the reaction mixture was incubated at room temperature for $1 \mathrm{~h} 30 \mathrm{~min}$ and the absorbance of the mixture was measured at $760 \mathrm{~nm}$, Gallic acid (20-140 mg/l) was used as standard for the calibration curve. The total polyphenols content was expressed as micrograms of gallic acid equivalents (GAE) per milligram of extract. All samples were analyzed in three replications.

\section{Determination of total flavonoids content}

The total flavonoids in plant extracts were determined using the aluminum trichloride $\left(\mathrm{AlCl}_{3}\right)$ method ${ }^{15}$. Briefly, $1 \mathrm{ml}$ of $2 \% \mathrm{AlCl}_{3}$ in methanol was mixed with $1 \mathrm{ml}$ of the extract. After incubation in dark at room temperature for $10 \mathrm{~min}$, the absorbance of the reaction mixture was measured at $430 \mathrm{~nm}$. Quercetin (1-40 mg/l) was used as standard for calibration curve and the total Flavonoids content was expressed as micrograms quercetin equivalent (QE) per milligram of extract.

\section{Evaluation of antioxidant activity \\ DPPH free radical-scavenging assay}

The free radical scavenging activity of the extracts was measured by 2,2- diphenyl-1-picrylhydrazyl(DPPH) assay 16 . After dissolving the aqueous extract in distilled water, the methanol extract in methanol, the solution of DPPH in methanol $(0.04 \mathrm{mg} / \mathrm{mL})$ was prepared and $1250 \mu \mathrm{L}$ of this solution was added to $50 \mu \mathrm{L}$ of extracts solution at different concentration. The mixture was shaken vigorously and then kept in the dark for 30 minutes at room temperature. Then, the absorbance was measured at $517 \mathrm{~nm}$. BHT and gallic acid were used as standards. All tests were performed in triplicate. Radical-scavenging activity was calculated using the following equation:

radical scavenging activity $(\%)=\left(\mathrm{A}_{\text {blank }}-\mathrm{A}_{\text {sample }} / \mathrm{A}_{\text {blank }}\right) \times 100$
A blank: Absorbance of the control.

A sample: Absorbance of the reagent with extract.

\section{$\boldsymbol{\beta}$-carotene/linoleic acid assay}

In this test, the antioxidant capacity of the extracts was determined by measuring the inhibition of the oxidative degradation of $\beta$-carotene (discoloration or bleaching) by the oxidation products of the acid linoleic 17 . The $\beta$-carotene solution was prepared by dissolving $0.5 \mathrm{mg} \beta$-carotene in 1 $\mathrm{mL}$ of chloroform. One milliliter of this solution was pipetted to a flask covered with aluminum foil. Then $25 \mu \mathrm{L}$ of linoleic acid and $200 \mathrm{mg}$ of tween 40 were added. The chloroform was evaporated using evaporator at $45^{\circ} \mathrm{C}$. Then $100 \mathrm{~mL}$ of distilled water saturated with oxygen was added. $2.5 \mathrm{~mL}$ of this prepared $\beta$-carotene solution were transferred to test tubes, and $350 \mu \mathrm{L}$ of the extracts $(2 \mathrm{mg} / \mathrm{mL}$ methanol) were added before incubation for $48 \mathrm{~h}$ at room temperature. The same procedure was repeated with butylated hydroxyl toluene (BHT) as a positive control and with methanol and distilled water as a negative control. The absorbance was reading at $490 \mathrm{~nm}$ after $1 \mathrm{~h}, 2 \mathrm{~h}, 6 \mathrm{~h}, 24 \mathrm{~h}$ and $48 \mathrm{~h}$. The antioxidant activity of extracts was calculated using the following equation:

$$
\mathrm{AA} \%=\mathrm{A}_{\text {sample }} / \mathrm{A}_{\text {Внт }} \times 100 .
$$

A sample: Absorbance in the presence of the extract; A внт: Absorbance in the presence of positive control BHT.

\section{Statistical Analyses}

The results are expressed as the mean \pm standard deviation. One-way analysis of variance (ANOVA) followed by the Tukey test was performed to assess differences between groups. Differences were considered significant at $\mathrm{p}<0.05$.

\section{RESULTS AND DISCUSSION}

The yields of aqueous and methanolic extract of leaves and flowers of Thymelaea hirsuta were $13.25 \%$ and $11.55 \%$ respectively.

\section{Total phenolic and flavonoid content}

Plant polyphenols are secondary metabolites characterized by one or more hydroxyl groups binding to one or more aromatic rings. Several thousand polyphenolic molecules have been identified in higher plants, including edible ones. Plant polyphenols are divided into two major groups, flavonoids and non-flavonoids. Flavonoids can be divided into flavanols, flavonols, anthocyanidins, flavones, flavanones, and chalcones. Non-flavonoids include stilbene, phenolic acids, saponin, and tannins. Among the important biological properties exhibited by plant polyphenols, their antioxidant activity has raised a great interest ${ }^{18}$.

Table 1 showed the total content of phenolics and flavonoids in extracts. AqE extract had a total phenolic content of $[57,95$ $\mu \mathrm{g}$ GAE/mg extract) and flavonoids $(4,59 \mu \mathrm{g} \mathrm{QE} / \mathrm{mg}$ extract), (10,66 $\mu \mathrm{g} \mathrm{RE} / \mathrm{mg}$ extract). while, Methanolic extract had a total phenolic content of $(295,22 \mu \mathrm{g} \mathrm{GAE} / \mathrm{mg}$ extract $)$ and flavonoids $(9,40 \pm 0,06 \mu \mathrm{g} \mathrm{QE} / \mathrm{mg}$ extract $),(26,42 \mu \mathrm{g}$ $\mathrm{QE} / \mathrm{mg}$ extract).

Table 1: Total polyphenols and flavonoids content of Thymelaea hirsuta extracts.

\begin{tabular}{cllc}
\hline Extract & \multicolumn{2}{c}{ Polyphenols } & \multicolumn{2}{c}{ Flavonoids } \\
\cline { 2 - 4 } & $\mu \mathrm{g}$ GAE$/$ mg extract & $\mu \mathrm{g} Q \mathrm{QE} / \mathrm{mg}$ extract & $\mu \mathrm{g} \mathrm{RE} / \mathrm{mg}$ extract \\
\hline $\mathrm{AqE}$ & 57,95 & 4,59 & 10,66 \\
$\mathrm{ME}$ & 295,22 & 9,40 & 26,42 \\
\hline
\end{tabular}

AqE : aqueous extract, ME : methanolic extract, GAE: gallic acid equivalent, QE: quercetin equivalent, RE: rutin equivalent. Each value represents the mean $\pm S D(n=3)$. 


\section{DPPH radical scavenging activity}

DPPH radical is a stable free radical that shows a maximum absorption at $517 \mathrm{~nm}$, and is widely used to evaluate the free radical scavenging ability of natural compounds. In the DPPH assay, the antioxidants were able to reduce the stable radical DPPH (purple color) to the yellow coloured diphenylpicrylhydrazine. Therefore, the antioxidant activities of a sample can be expressed as its ability in scavenging the DPPH radical ${ }^{19}$.

Results of DPPH scavenging activity of Thymelaea hirsuta extracts are given in Table 2. ME exhibited the highest activity toward DPPH scavenging $\left(\mathrm{IC}_{50}=0.030 \pm 0.004\right.$ $\mathrm{mg} / \mathrm{ml}$ ) followed by AqE with ( $\mathrm{IC}_{50}=0.275 \pm 0.019 \mathrm{mg} / \mathrm{ml}$ ).

Table 2: DPPH scavenging activity of Thymelaea hirsuta extracts and standards.

\begin{tabular}{cc}
\hline Extracts & $\mathrm{IC}_{50}(\mathrm{mg} / \mathrm{mL})$ \\
\hline AqE & $0.275 \pm 0.019$ \\
ME & $0.030 \pm 0.004$ \\
Gallic acid & $0.001 \pm 0.000^{\#}$ \\
BHT & $0.043 \pm 0.003^{\#}$ \\
\hline glml. Each value represents the mean $\pm \mathrm{SD}(\mathrm{n}=3)$.
\end{tabular}

\section{$\beta$-carotene/linoleic acid bleaching assay}

The results of the inhibition of $\beta$-carotene oxidation in the presence of extracts after 24 hours of incubation was presented in table 3. The antioxidant activity of the tow extracts in the $\beta$-carotene/linoleic acid assay was (41.05 \pm $2.72 \%)$ for the methanolic extract and $(39.1 \pm 1.33 \%)$ for the aqueous extract.

Table 3 : Antioxidant activities of Thymelaea hirsuta extracts at 24 hours of incubation measured by $\beta$-carotene bleaching method.

\begin{tabular}{cc}
\hline Extracts & Inhibition \% \\
\hline AqE & $39.1 \pm 1.33$ \\
ME & $41.05 \pm 2.72$ \\
BHT & $100 \pm 2.76$ \\
H2O & $9.162 \pm 0.528$ \\
methanol & $33.83 \pm 2.891$ \\
\hline
\end{tabular}

Each value represents the mean \pm SD $(n=3)$.

Thymelaea hirsuta extracts are rich sources of natural antioxidants which appears to be an alternative to synthetic antioxidants. The chemical composition of flower, stem and leaf of Thymelaea hirsuta indicated the presence of phenolic compounds including flavonoids, which are known to possess antioxidant activities 20 . In general the antioxidant activity of phenolic compounds reportedly varies with the structure and degree of hydroxylation of the aromatic ring 21 22. It is associated with the number of hydroxyl groups and the most active possess from 3 to 6 hydroxyl groups. Hydroxylation in the $\mathrm{C} 3$ position seems to be detrimental for their antioxidant potency 23. Fukumoto and Mazza 24 reported that for benzoic and cinnamic acid derivatives, flavonols and anthocyanidins, an increase in the number of hydroxyl groups on the aromatic ring lead to higher antioxidant activity in vitro. Compounds with three hydroxyl groups on the phenyl ring of phenolic acids or the B-ring of flavonoids had high antioxidant activity. The loss of one hydroxyl group decreased activity slightly. Moreover, screening of phytochemical compounds in Thymelaea hirsuta revealed the presence of tannins, alkaloids, steroids, saponins, coumarins, reducteurs compound and anthraquinones. The antioxidant activities of Thymelaea hirsuta extract are due to the presence of these phytochemicals ${ }^{20}$.

\section{CONCLUSION}

The present study aimed to evaluate the in vitro Antioxidant activity of extracts prepared from the leaves and flowers of Thymelaea hirsuta. The results showed that The extracts exhibited antiradical activities toward 2,2'- diphenyl-1picrylhydrazyl (DPPH) and inhibiting lipid peroxidation.

\section{ACKNOWLEDGEMENT}

This work was supported by the Algerian Ministry of Higher Education and Scientific Research (MERS) and by the Algerian Agency for the Development of Research in Health (ANDRS). We express our gratitude to these organizations.

\section{REFERENCES}

1. Valento P, Fernandes E, Carvalho F, Andrade PB, Seabra RM, Bastos ML. Antioxidant activity of Hypericum androsaemum Infusion: Scavenging Activity against Superoxide Radical, Hydroxyl Radical and Hypochlorous Acid. Biol. Pharm. Bull. 2002; 25:1320-1323.

2. Gulcin I, Oktay M, Kirecci E, Kufrevioglu OI.. Screening of antioxidant and antimicrobial activities of anise (Pimpinella anisum L.) seed extracts. Food Chem. 2003; 83:371-382.

3. Kourounakis AP, Galanakis D, and Tsiakitzis K. Synthesis and pharmacological evaluation of novel derivatives of antiinflammatory drugs with increased antioxidant and antiinflammatory activities. Drug Dev Res. 1999 47:9-16.

4. Gulcin I, Buyukokuroglu ME, Oktay $M$ and Kufrevioglu IO Antioxidant and analgesic activities of turpentine of Pinus nigra Arn. Subsp. Pallsiana (Lamb). Holmboe J Ethnopharmacol. 2003; 86:51-58.

5. Halliwell B. Biochemistry of Oxidative Stress Bioche- chemical Society Transactions. 2007; 35:1147-1150.

6. Liu RH. Potential synergy of phytochemicals in cancer prevention: mechanism of action. The Journal of Nutrition. 2004; 134:34793485 .

7. Jeong SM, Kim SY, Kim DR, Nam KC, Ahn DU and Lee SC. Effect of seed roasting conditions on the antioxidant activity of defatted sesame meal extracts. Food Chem. Toxicol. 2004; 69:377-381.

8. Akrout LA, Gonzalez H, El Jani PC. Antioxidant and antitumor activities of Artemisia campestris and Thymelaea hirsuta from southern Tunisia, Food Chem. Toxicol. 2011; 49:342-349.

9. Kawano M, Matsuyama K, Miyamae Y, Shinmoto H, Kchouk ME, Morio T, Shigemori H, Isoda H. Antimelanogenesis effect of Tunisian herb Thymelaea hirsuta extract on B16 murine melanoma cells, Exp Dermatol. 2007; 16:977-984.

10. Villareal MO, Han J, Yamada P, Shigemori H, Isoda H. Hirseins inhibit melanogenesis by regulating the gene expressions of Mitf and melanogenesis enzymes. Exp. Dermatol. 2010; 19(5):450-7.

11. Bnouham M, Merhfour FZ, Legssyer A, Mekhfi H, Maâllem S, Ziyyat A. Antihyperglycemic activity of Arbutus unedo, Ammoides pusilla, and Thymelaea hirsuta. Pharmazie. 2007; 62(8):630-632.

12. El Amrani F, Rhallab A, Alaoui T, El Badaoui K, Chakir S. 2009. Hypoglycemic effect of Thymelaea hirsuta in normal and streptozotocin-induced diabetic rats. J. Med. Plant. Res. 3 : 625629

13. Djeridane M, Yousfi B, Nadjemi D, Boutassouna, Stocker P, Vidal N. Antioxidant activity of some Algerian medicinal plants extracts containing phenolic compounds, Food.Chem. 2006; 97:654-660.

14. Li HB, Cheng KW, Wong CC, Fan KW, Chen F, Jiang Y. Evaluation of antioxidant capacity and total phenolic content of different 
fractions of selected microalgae. Food Chemistry. 2007; 102:771-776.

15. Bahorun T, Gressier B, Trotin F, Brunete C, Dine T, Vasseur J, Gazin JC, Pinkas M, Luycky M, Gazin M. Oxygen species scavenging activity of phenolic extract from Hawthorn fresh plant organs and pharmaceutical preparation. Drug Research. 1996; 16.

16. Burits M, Bucar F. Antioxidant activity of Nigella sativa essential oil. Phytotherapy Researc. 2000; 14:323-328.

17. Kartal N, Sokmen M, Tepe B, Daferera D, Polissiou M, Sokmen A. Investigation of the antioxidant properties of Ferula orientalis L. using a suitable extraction procedure. Food chemistry. 2007; 100:584-589.

18. Zhou Y, Jiang Z, Lu H, Xu Z, Tong R, Shi J, Jia, G. Recent Advances of Natural Polyphenols Activators for Keap1-Nrf2 Signaling Pathway. Chem. Biodivers. 2019; 16.

19. Conforti F, Loizzo MR, Statti GA, Menichini F. Comparative radical scavenging and anti diabetic activities of methanolic extract and fractions from Achillea ligustica. AllBiol Pharm Bull. 2005; 28:1791-1794.

20. Amari NO, Bouzouina M, Berkani A, Lotmani B. Phytochemical screening and antioxidant capacity of the aerial parts of Thymelaea hirsuta L. Asian Pacific journal of tropical disease, 2014; 4:104-109.

21. Burda S and Oleszek W. Antioxidant and antiradical activities of flavonoids. Journal of Agricultural and Food Chemistry. 2001; 49:2774-2779.

22. Aruoma 0 I. Methodological considerations for characterizing potential antioxidantactions of bioactive components in plant foods. Mutation Research. 2002; 9(20):523-524.

23. Huguet AI, Manez S and Alcaraz MJ. Superoxide scavenging properties of flavonoids in a non-enzymic system. Z. Naturforsch. 1990; 45:19-24.

24. Fukumoto LR and Mazza G. Assessing antioxidant and prooxidant activities of phenolic compounds. Journal of Agricultural and Food Chemistry. 2000; 48:3597-3604. 